\title{
Creep Damage Analysis of Mod.9Cr-1Mo Steel Welds Considering Void Mechanics Modeling
}

\author{
Takashi Honda ${ }^{1 *}$, Takuya Fukahori ${ }^{1}$, Takumi Tokiyoshi ${ }^{1 *}$, Yasuharu Chuman ${ }^{1}$, \\ Toshihide Igari ${ }^{1 *}$ and Alan Cocks ${ }^{2} *$ \\ ${ }^{1}$ Research and Innovation Center, Mitsubishi Heavy Industries, LTD., 5-717-1, Fukahori-machi, Nagasaki, Japan \\ 2 Department of Engineering Science, University of Oxford, Parks Road, Oxford, UK \\ takashi3_honda@mhi.co.jp
}

Introduction. Since creep strength reduction of mod.9Cr-1Mo steel welds was confirmed, development of evaluation method for Type IV failure is required for adequate maintenance of USC power plants after long service. The mechanism of Type IV creep failure within the FGHAZ (fine-grained heat affected zone) is two fold; an increase in number density of creep voids with a size of comparable to the FGHAZ grain size $(5 \mu \mathrm{m})$, and a strain softening in the last stage of creep life. In this paper, a creep damage analysis scheme considering the above two mechanisms ${ }^{(1)}$ was applied to welded joints with non-uniform weld metal materials of weld metal, HAZ and base metal. Both the creep void density distribution and the failure process with crack initiation, propagation and final rupture predicted by the analysis are compared with experimental results at $650^{\circ} \mathrm{C}$.

Creep damage analysis scheme. A void mechanics model expresses the increase of number density of creep voids (creep void density in brevity) in terms of a strain for void nucleation, which is strongly influenced by the multiaxial state of stress. A critical value of creep void density corresponding to initiation of a micro-crack is determined based on the results of a random-fracture-resistance model of grain boundaries by the authors of this paper.

Creep strain rate is expressed as Eq.(1), where secondary creep rate is a base line and acceleration by both the damage and softening is considered.

$$
\dot{\varepsilon}_{i j}^{c}=\frac{3}{2} A \sinh \left[\frac{B \sigma_{e q}}{(1-G)(1-D)}\right] \frac{\sigma_{i j}^{D}}{\sigma_{e q}}
$$

The damage $\mathrm{D}$ is defined as Eq.(2), where $\mathrm{N}$ is the number density of creep void and is defined as Eq.(3).

$$
\begin{aligned}
& D=\frac{N}{40000} \\
& \dot{N}=a \dot{\varepsilon}_{e}^{c}\left(\frac{4}{9}+\frac{20}{9} X^{2}\right)
\end{aligned}
$$

A critical value of damage corresponding to micro crack initiation at $\mathrm{N}=4,000 / \mathrm{mm}^{2}$ is Dcr $=0.1$. The strain softening parameter $\mathrm{G}$ is composed of strain and thermal softening, just as expressed in the previous works $^{(1)(2)}$.

Creep properties of FGHAZ. Since the critical damage is small (0.1), the role of the strain sotening parameter $G$ is important in expressing the tertiary creep and rupture time of the FGHAZ. Stress dependence in creep strain rate and rupture time is key to predict the rupture time of welded joints. Figure 1(a)
\& (b) respectively express the minimum creep rate and rupture time in terms of applied stress ${ }^{(2)(3)}$. A von Mises stress level in FGHAZ U- and X-shape welds is respectively around $25 \mathrm{MPa}$ and $35 \mathrm{MPa}{ }^{(2)}$, which is lower than the remote tensile stress of 66MPa.

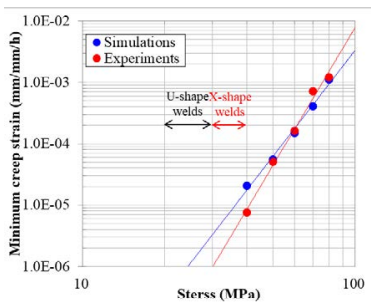

(a)

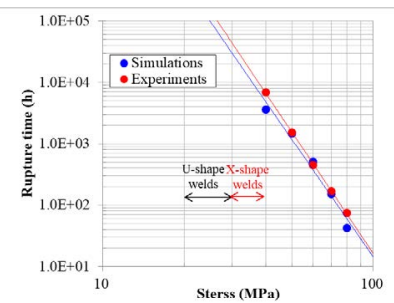

(b)
Fig.1 Relationship of stress and (a) minimum creep strain rate and (b) rupture time

Creep damage analysis results. An improved set of material parameters covering low stress levels in Uand $\mathrm{X}$-shape welds was employed in the creep damage analysis. Both a uniform model (Model-1) and a gradient material model (Model-2) considering the hardness distribution in FGHAZ are used. An example of the analysis results of creep void density in Model-2 close to the rupture time is shown in Fig.2 for U-shape welds. FEM elements with creep void density exceeding $4000 / \mathrm{mm}^{2}$ are designated as black. A difference in damage and rupture time from Model-1 and Model-2 is found to be small. Rupture times in Uand $\mathrm{X}$-shape welds are improved when compared with previous results ${ }^{(2)}$.

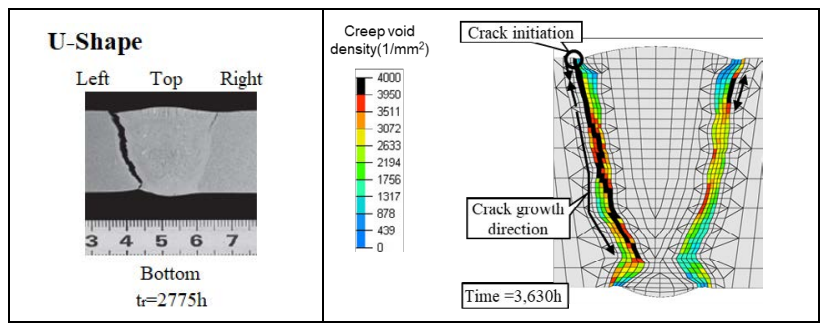

Fig.2 Creep void density at rupture time from damage analysis of U-shape weld specimen

\section{References.}

(1) Honda, T. et al., JSME Mech. Eng. Journal, 4 (2017)

(2) Honda, T. et al., J. Japan Society of Materials Sciences, 68 (2019)

(3) Arisue, K. et al., EPRI Workshop (2019) 